УДК 598.2(571.6)

К ВОПРОСУ О ЦЕЛЕСООБРАЗНОСТИ ВКЛЮЧЕНИЯ ОВСЯНКИ-РЕМЕЗА OCYRIS RUSTICUS PALLAS, 1776 В КРАСНУЮ КНИГУ РОССИЙСКОЙ ФЕДЕРАЦИИ

\author{
М.Ф. Бисеров ${ }^{1,2}$, Е.А. Медведева ${ }^{1}$ \\ ${ }^{1}$ Государственный природный заповедник «Буреинский», \\ ул. Зеленая 3, п. Чегдомын, Верхнебуреинский р-н, 682030, \\ e-mail: marat-biserov@mail.ru; \\ ${ }^{2}$ Государственный заповедник «Бастак», \\ ул. Шолом-Алейхема 69а, г. Биробиджан, 679016, \\ e-mail: medvedeva@itig.as.khb.ru
}

\begin{abstract}
В работе раскрыты возможные причины того, почему в последние годы овсянка-ремез Ocyris rusticus - вид, до недавнего времени считавшийся многочисленным повсеместно в пределах ареала, стал относиться рядом специалистов к видам, глобальные тренды численности которых вызывают большие опасения, вплоть до предложений о включении этого вида в Красную книгу России.
\end{abstract}

Ключевые слова: овсянка-ремез, Ocyris rusticus, численность, Дальний Восток.

Образец цитирования: Бисеров М.Ф., Медведева Е.А. К вопросу о целесообразности включения овсянки-ремеза Ocyris Rusticus Pallas, 1776 в Красную книгу Российской Федерации // Региональные проблемы. 2021. Т. 24, № 2-3. С. 94-98. DOI: 10.31433/2618-9593-202124-2-3-94-98.

Овсянка-ремез Ocyris rusticus Pallas, 1776 ранее практически повсеместно на пространствах своего ареала, занимающего таёжную зону от Скандинавии до Чукотки и Камчатки, считалась обычным или многочисленным видом. Однако в последнее десятилетие её всё чаще стали относить к видам, глобальные тренды численности которых вызывают у ряда специалистов большие опасения. Так, утверждается, что только за 2005-2015 гг. отмечено снижение численности всей популяции вида на 32-91\% [15].

Из ряда работ, основанных на на- блюдениях, проведённых в Амурской области и Приморском крае $[2,7,16]$, так же следует, что и на Дальнем Востоке численность овсянки-ремеза стала соответствовать тренду, выявленному для всего ареала. Дошло до того, что в настоящее время вид включён в Красную книгу России.

Между тем практически все известные нам источники, относящиеся к периоду 2005-2019 гг., свидетельствуют о том, что овсянка-ремез в Сибири и на Дальнем Востоке по-прежнему обычный и многочисленный вид. Так, на большей части гор северо-восточной 
Сибири овсянка-ремез обычна и многочисленна на гнездовании [11]. На Камчатке она продолжает оставаться одним из самых многочисленных гнездящихся видов. Данные за последние 17 лет показывают, что ярко выраженной отрицательной тенденции изменения численности там не отмечается, хотя ежегодные колебания плотности населения в разные годы на одной и той же территории могут превышать 2 раза [8].

Наблюдения на Буреинском нагорье также свидетельствуют о том, что в рассматриваемый период времени, вплоть до 2020 г., овсянка-ремез на весеннем и осеннем пролёте многочисленна, а местами весьма многочисленна [1, 3-5].

В Приморском крае это многочисленный пролётный вид [9]. На крайнем юге Приморья, где была замечена многолетняя тенденция резкого сокращения численности многих видов птиц, в том числе и овсянки-ремеза, данный вид, тем не менее, является ежегодно доминирующим, одновременно являясь одним из самых массовых транзитных мигрантов [6]. По данным В.П. Шохрина (2017), вид обычен или многочислен, однако бывают годы, когда полёт практически отсутствует.

Расхождения в представлении о численности вида, скорее всего, объясняются несколькими причинами. Известно, например, что заметные межгодовые колебания численности многих северных видов птиц на местах гнездования связаны с экологическими факторами, воздействующими на них, что в своё время было подробно рассмотрено А.А. Кищинским (1983).

Значительные видимые колебания численности вида и полное отсутствие встреч в отдельные годы, отмечаемые на стационарных пунктах наблюдений, расположенных на путях миграций, можно объяснить значительными колебаниями численности на местах гнездования и сменой миграционных маршрутов вида, имеющего обыкновение мигрировать стаями, что было установлено при сравнении хода весеннего пролёта овсянки-ремеза в окраинных и внутренних районах Буреинского нагорья [5]. Подтверждением данного вывода являются наблюдения за пролётом овсянок-ремезов в Ленинградской области, в ходе которых специальный выбор времени и места работ показал, что данный вид, как и некоторые другие, относительно редко отмечавшиеся в определённой местности, не столь уж редок, как это принято считать, а обычен и даже многочислен [12].

Наши наблюдения показали, что по годам 2-3-кратные колебания численности в период весенней миграции сопоставимы с таковыми на местах гнездования, что свидетельствует об относительно благополучном состоянии популяции во время пребывания на местах зимовок [5].

Примечательно, что для юга европейской части России недавно сделан вывод, наоборот, об увеличении численности этого вида [13].

Таким образом, на пространствах Сибири и Дальнего Востока овсянка-ремез по-прежнему обычна и многочисленна на гнездовании и пролёте, из чего следует, что для включения этого вида в Красную книгу РФ нет оснований. Более того, включение в Красную книгу страны вида, столь обычного и 
многочисленного в восточной части ареала, может в дальнейшем сыграть негативную роль при освоении пространств Севера, Сибири и Дальнего Востока.

\section{ЛИТЕРАТУРА:}

1. Аверин А.А., Антонов А.И., Питтиус У. Класс Aves - Птицы // Животный мир заповедника «Бастак». Благовещенск: БГПУ, 2012. С. 171-208.

2. Антонов А.И., Дугинцов В.А. Аннотированный список видов птиц Амурской области // Амурский зоологический журнал. 2018. Т. 10, № 1. С. 11-79.

3. Бисеров М.Ф. Птицы Буреинского заповедника и прилегающих территорий // Труды Буреинского заповедника. Хабаровск: ИВЭП ДВО РАН, 2003. Вып. 2. С. 56-83.

4. Бисеров М.Ф. Материалы по орнитофауне заповедника «Бастак»// Труды Буреинского заповедника. Хабаровск: ИВЭП ДВО РАН, 2003. Вып. 2. С. 83-97.

5. Бисеров М.Ф. Весенняя миграция овсянки-ремеза Ocyris rusticus на Буреинском нагорье // Русский орнитологический журнал. 2020. Т. 29. Экспресс-выпуск, № 1885. С. $583-$ 600.

6. Вальчук О.П., Лелюхина Е.В. Разнообразие осенних миграционных стратегий овсянковых в Южном Приморье // 14-я Международная орнитологическая конференция Северной Евразии. Алматы, 2015. C. 97-98.

7. Вальчук О.П., Масловский К.С., Лелюхина Е.В., Ириняков Д.С., Гордиенко И.Н., Прокопенко О.Д., Горбунова П.М. Многолетняя динамика и тренды численности некоторых воробьиных птиц в периоды миграций в Южном Приморье // Динамика численности птиц в наземных ландшафтах: материалы Всерос. конф. М.: Тов-во науч. изданий КМК, 2017. C. $100-108$.

8. Герасимов Ю.Н., Герасимов Н.Н., Бухалова Р.В. Овсянка-ремез Ocyris rusticus на Камчатке // Русский орнитологический журнал. 2019. Т. 28. Экспресс-выпуск, № 1726. С. 487490.

9. Глущенко Ю.Н. Птицы Приморского края: краткий фаунистический обзор / Ю.Н. Глущенко, В.А. Нечаев, Я.А. Редькин. М.: Тов-во науч. изданий КМК, 2016. 523 с.

10.Кищинский А.А. О структуре и динамике областей гнездования птиц на Севере // Труды Зоологического института АН СССР. 1983. Вып. 116. C. 47-57.

11.Мелихова Е.В. География фауны птиц гор Северо-Восточной Сибири: дис. ... канд. геогр. наук. М., 2018. $181 \mathrm{c}$.

12.Носков Г.А. Некоторые данные о пролёте «редких» видов птиц в Ленинградской области // Русский орнитологический журнал. 2015. Т. 24, № 1198. С. 3608-3609.

13.Савицкий Р.М. Овсянка-ремез Emberiza rustica на юге Европейской России // Международный журнал прикладных и фундаментальных исследований. 2015. № 11-12. C. $277-299$.

14.Шохрин В.П. Птицы Лазовского заповедника и сопредельных территорий. Лазо: Дальпресс, 2017. 648 с. 
15.Edenius L., Choi C., Heim W., Jaakkonen T., De Jong A., Ozaki K., Roberge J. The next common and widespread bunting to go? Global population decline in the Rustic Bunting Emberiza rustica // Bird Conservation International. 2016. April. P. 1-10.

16. Heim W. Population declines in eastern Palaearctic passerines // Vogelwelt. 2017. Vol. 137. P. 181-183.

\section{REFERENCES}

1. Averin A.A., Antonov A.I., Pittius U. Aves class-Birds, in Zhivotnyi mir zapovednika «Bastak» (Animal world of the "Bastak" Nature Reserve). Blagoveshchensk: BSPU, 2012, pp. 171-208. (In Russ.).

2. Antonov A.I., Dugintsov V.A. Annotated Bird Species List of Amur Oblast. Amurskii zoologicheskii zhurnal, 2018, vol.10, no. 1, pp.11-79. (In Russ.).

3. Biserov M.F. Birds of the Bureinsky Nature Reserve and adjacent territories, in Trudy Bureinskogo zapovednika (Trudy Bureinsky Nature Reserve). Khabarovsk: IVEP FEB RAS, 2003, no. 2, pp. 56-83. (In Russ.).

4. Biserov M.F. Materials on the avifauna of the "Bastak" nature Reserve, in Trudy Bureinskogo zapovednika (Trudy Bureinsky Nature Reserve). Khabarovsk: IVEP FEB RAS, 2003, no. 2, pp.83-97. (In Russ.).

5. Biserov M.F. Spring migration of oatmeal-remez Ocyris rusticus in the Bureinsky highlands. Russkii ornitologicheskii zhurnal, 2020, vol. 29, ekspress-vypusk, no. 1885, pp. 583-600. (In Russ.).

6. Valchuk O.P., Lrlyukhina E.V. Variety of autumn migration policies of
Emberizidae in Southern Primorye, in 14-ya Mezhdunarodnaya ornitologicheskaya konferentsiya Severnoi Evrazii (XIV International Ornithological Conference of Northern Eurasia). Almaty, 2015, pp. 97-98. (In Russ.).

7. Valchuk O.P., Maslovsky K.S., Leliuchina E.V., Irinyakov D.S., Gordienko I.N., Prokopenko O.D., Gorbunova P.M. Long-Term Dynamic and Trends in the Abundance of Some Passerine Birds During Migration in Southern Primorye // Dinamika chislennosti ptits $v$ nazemnykh landshaftakh: materialy Vseros. konf. (Population dynamics of birds in terrestrial landscapes). Moscow: KMK Scientific Press, 2017, pp. 100108. (In Russ.).

8. Gerasimov Yu.N., Gerasimov N.N.,Bukhalova R.B. The Rustic Bunting Ocyris Rusticus on Kamchatka. Russkii ornitologicheskii zhurnal, 2019, vol. 28, ekspressvypusk, no. 1726, pp. 487-490. (In Russ.).

9. GlushchenkoYu.N.PtitsyPrimorskogo kraya: kratkii faunisticheskii obzor (Birds of Primorsky krai: brief review of the fauna). Yu.N. Glushchenko, V.A. Nechaev, Ya.A. Red'kin. Moscow: KMK Scientific Press, 2016. 523 p. (In Russ.).

10. Kishchinskii A.A. On the structure and dynamics of bird nesting areas in the North. Trudy Zoologicheskogo instituta AN SSSR, 1983, no. 116, pp. 47-57. (In Russ.).

11. Melikhova E.V. Geography of the bird fauna of the mountains of NorthEastern Siberia. Dissertation of cand. 
Sci. (geogr.). Moscow, 2018. 181 p. (In Russ.).

12. Noskov G.A. Some Data on the Migration of "Rare" Species of Birds in the Leningrad Region. Russkii ornitologicheskii zhurnal. 2015. vol. 24, no. 1198, pp. 3608-3609. (In Russ.).

13. Savitsky R.M. Expansion of the Areal of Rustic Bunting Emberiza Rustica on the South of Europe Russia. Mezhdunarodnyi zhurnal prikladnykh ifundamental'nykh issledovanii, 2015, no. 11-12, pp. 277-299. (In Russ.).

14. Shokhrin V.P. Ptitsy Lazovskogo zapovednika i sopredel'nykh territorii
(Birds of the Lazovsky Nature Reserve and adjacent territories). Lazo: Dal'press Publ., 2017. 648 p. (In Russ.).

15. Edenius L., Choi C., Heim W., Jaakkonen T., De Jong A., Ozaki K., Roberge J. The next common and widespread bunting to go? Global population decline in the Rustic Bunting Emberiza rustica. Bird Conservation International, 2016, April, pp. 1-10.

16. Heim W. Population declines in eastern Palaearctic passerines. Vogelwelt, 2017, vol. 137, pp. 181-183.

\title{
ON THE ISSUE OF EXPEDIENCY OF THE RUSTIC BUNTING OCYRIS RUSTICUS PALLAS, 1776, INCLUSION IN THE RED DATA BOOK OF THE RUSSIAN FEDERATION
}

\author{
M.F. Biserov, E.A. Medvedeva
}

The work reveals possible reasons why in recent years the Rustic Bunting Ocyris rusticus - the species, which had previously been considered numerous within its habitat, began to be treated by a number of experts as a decreasing one, up to their offers to include this species in the Red Data Book of Russia.

Keywords: Rustic Bunting, Ocyris rusticus, number, Far East of Russia.

Reference: Biserov M.F., Medvedeva E.A. On the issue of expediency of the rustic bunting Ocyris Rusticus Pallas, 1776, inclusion in the Red Data Book of the Russian Federation. Regional'nye problemy, 2021, vol. 24, no. 2-3, pp. 94-98. (In Russ.). DOI: 10.31433/2618-9593-2021-24-2-3-9498. 